\title{
ASSINATURAS MAGNÉTICAS E GRAVIMÉTRICAS DO ARCABOUÇO ESTRUTURAL DA BACIA POTIGUAR EMERSA, NE DO BRASIL
}

\author{
Nilo Costa Pedrosa Jr. ${ }^{1,2}$, David Lopes de Castro³ e João Paulo Lopes de Matos ${ }^{1,2}$ \\ Recebido em 9 setembro, 2009 / Aceito em 11 março, 2010 \\ Received on September 9, 2009 / Accepted on March 11, 2010
}

\begin{abstract}
This work presents a qualitative interpretation of aeromagnetic and gravity signatures of the onshore Potiguar Basin structural framework, located in the northern portion of the Borborema Province. The Precambrian basement consists of the amalgamation of Archaean and Proterozoic crustal blocks, formed by several lithostratigraphic sequences of igneous and metamorphic rocks. These geological units are partially underlain by more than $6000 \mathrm{~m}$ thick Cretaceous sedimentary strata of the Potiguar Basin and deposits of Tertiary and Quaternary age. The regional structural framework is controlled by reactivation of Neoproterozoic shear zones, which culminated to the South Atlantic opening in the Cretaceous. In this sense, the study of the Potiguar basin tectonic evolution in Mesozoic depends on the knowledge of the plot structural Precambrian and its relationship with the internal architecture of the basin. The integrated interpretation of geophysical data allowed the characterization of six distinct magnetic and gravity domains correlated to the main geotectonic blocks. The internal geometry of the main rift structure could be well delineated in the various geophysical maps. The rift internal architecture is in the regional geotectonic setting, whose structural framework preferentially trends to NE-SW direction. The depocenters and internal basement highs are strongly NE-SW oriented. It was also possible to identify discontinuities in magnetic and gravity lineaments, which provide new evidences for the basement structural control on the distribution of normal and transfer faults, which outline the rift architecture.
\end{abstract}

Keywords: geophysical mapping, potential methods, Potiguar Basin.

RESUMO. Apresenta-se nesse trabalho uma interpretação qualitativa das assinaturas aeromagnética e gravimétrica do arcabouço estrutural da Bacia Potiguar emersa, situada na porção setentrional da Província Borborema. 0 embasamento pré-cambriano consiste da amalgamação de blocos crustais arqueanos e proterozóicos, formados por diversas sequências litoestratigráficas de rochas ígneas e metamórficas. Estas unidades geológicas são parcialmente recobertas por um expressivo pacote sedimentar cretáceo, de até $6000 \mathrm{~m}$ de espessura, da Bacia Potiguar e depósitos de idades terciária e quaternária. 0 contexto geotectônico regional encontra-se condicionado por extensas zonas de cisalhamento neoproterozóicas, que foram reativadas por esforços distensionais associados à abertura do Atlântico Sul no Cretáceo Inferior. Neste sentido, o estudo da evolução tectônica mesozóica da Bacia Potiguar passa pelo conhecimento da trama estrutural pré-cambriana e sua relação com a arquitetura interna da bacia. A interpretação integrada dos dados geofísicos permitiu a caracterização de seis domínios magnéticos e gravimétricos distintos para 0 arcabouço regional da Bacia Potiguar, que podem ser correlacionados com os principais blocos geotectônicos da região. A arquitetura do rifte principal da bacia pôde ser bem delineada nos diversos mapas geofísicos, estando esta inserida na configuração geotectônica regional, cujo trend estrutural tem direção principal NE-SW. As estruturas internas da bacia, como depocentros e altos estruturais internos, são também orientadas na direção preferencial NE-SW. Foi possível identificar descontinuidades nos lineamentos magnéticos e gravimétricos, que fornecem novas evidências para o controle estrutural do embasamento sobre a distribuição de falhas normais e de transferência, que afetaram as rochas sedimentares meso-cenozóicas da bacia.

Palavras-chave: cartografia geofísica, métodos potenciais, Bacia Potiguar.

\footnotetext{
Campus Universitário do PICI, Bloco 913, 60455-760 Fortaleza, CE, Brasil. Tel./Fax: (85) 3366-9870 / 3366-9878 - E-mails: nilojuniorp@yahoo.com.br; jovempan@gmail.com

1 Programa de Pós-Graduação em Geologia - Universidade Federal do Ceará

2 Laboratório de Geofísica de Prospecção e Sensoriamento Remoto (LGPSR) - Departamento de Geologia - Universidade Federal do Ceará.

3 Departamento de Geologia - Universidade Federal do Rio Grande do Norte. Campus Universitário, s/n, 59072-970 Natal, RN, Brasil. Tel.: (84) 3215-3808 -E-mail: david@geologia.ufrn.br
} 


\section{INTRODUÇÃo}

Atualmente, vários trabalhos tentam esclarecer a influência de heterogeneidades crustais no controle estrutural e evolução tectonosedimentar de bacias rifte, com a reativação de uma litosfera continental previamente deformada (de Castro et al., 2007). Sendo assim, variações composicionais da crosta superior e feições estruturais pré-existentes têm um papel fundamental na reorganização da litosfera e na acomodação de deformações distensionais (Nicolas et al., 1994).

Um entendimento fundamental sobre as relações entre a deformação distensional, a estruturação pretérita e reativações de estruturas do embasamento, e a arquitetura do rifte resultante pode ser obtido através da interpretação integrada de dados magnéticos e gravimétricos, especialmente em bacias terrestres, onde dados de reflexão sísmica e informações de poços não são amplamente disponíveis.

Sykes (1978) e Boyce \& Morris (2002) chamaram a atenção para 0 tectonismo intraplaca e revelaram a existência de zonas de fraquezas na crosta continental, em regiões de bacias do tipo rifte com falhas profundas, como é o caso da Bacia Potiguar, que poderiam ser reativadas por tensões geradas a uma certa distância dos limites de placas.

Neste sentido, o objetivo principal da presente pesquisa é caracterizar 0 arcabouço estrutural da Bacia Potiguar emersa, com base nas assinaturas magnética e gravimétrica e, em especial, interpretar de forma integrada as unidades e os lineamentos geofísicos, com vistas ao estudo da evolução geotectônica da região. Os resultados obtidos fornecem importantes subsídios para determinar as relações estruturais entre os processos geotectônicos que geraram a bacia e a herança estrutural pré-rifte.

\section{CONTEXTO GEOLÓGICO}

A Bacia Potiguar situa-se no extremo nordeste brasileiro, compreende cerca de $100.000 \mathrm{~km}^{2}$ de área superficial e abrange parte dos estados do Rio Grande do Norte e Ceará (Fig. 1). Em termos geotectônicos, está inserida na porção setentrional da Província Borborema, que compreende amplo segmento geológico précambriano, estruturado durante 0 Ciclo Pan-Africano/Brasiliano (Neoproterozóico) e caracteriza-se por um arranjo complexo de domínios tectono-estratigráficos, limitados por zonas de cisalhamento regionais e por intenso magmatismo granítico (Almeida et al., 2000; Fetter et al., 2003).

No Domínio Rio Grande do Norte (DRN), o Maciço São José do Campestre, situado próximo à cidade de Natal, é o núcleo Arqueano mais antigo da Província Borborema (Dantas et al., 2004), sendo dominado por diatexitos e metatexitos com afinidades com rochas do tipo TTG, rochas máficas intrusivas e plutons neoarqueanos. 0 Complexo Gnáissico-Migmatítico reúne os litotipos paleoproterozóicos dos complexos Caicó, no Rio Grande do Norte, e Jaguaretama, no Ceará, que compõem grande parte do embasamento cristalino em toda porção sul da área (Angelim, 2006). Sua composição é essencialmente de ortognaisses tonalíticos a granodioríticos, geralmente metamorfisados sob condições de fácies anfibolito alto, apresentando graus variados de migmatização. 0 Grupo Seridó trata-se de uma sequência de rochas metassedimentares aflorantes no leste do Rio Grande do Norte, estruturadas durante a Orogênese Brasiliana. Compreende as formações, da base para o topo, Jucurutu, Equador e Seridó. A Zona de Cisalhamento Picuí-João Câmara (ZCPJC) está marcada segundo a direção NNE-SSW, exibindo uma cinemática transcorrente dextral (Jardim de Sá, 1994), a qual marca o contato entre as rochas do Complexo Gnáissico-Migmatíitico e as metasupracrustais do Grupo Seridó.

No Domínio Ceará Central (DCC), o Complexo Ceará (Paleoproterozóico) é representando pelas unidades Canindé e Independência, que se caracterizam por uma sequência típica de terrenos de rochas metassedimentares, dominada por metapelitos (CPRM, 2003). As associações litológicas são compostas por camadas de quartzitos, alguns minerais ricos em alumínio, lentes de mármores e rochas calciossilicáticas, frequentemente associadas com anfibolitos, compondo, segundo Vasconcelos et al. (1998), uma típica sequência depositada em ambiente marinho plataformal. A Faixa Orós-Jaguaribe está localizada no limite oeste da Bacia Potiguar e é composta por duas faixas móveis estreitas, limitadas pelas zonas de cisalhamento Óros (ZCO) e Jaguaribe (ZCJ) (Fig. 1), estando sobrepostas ao Complexo GnáissicoMigmatíitico, cuja evolução iniciou-se em torno de 1,9 Ga (Parente \& Arthaud, 1995). É constituída por sequências metavulcanosedimentares recortadas por derrames de rochas ácidas e máficas. A porção setentrional da Província Borborema é ainda, ocupada por intenso volume de suítes granitóides neoproterozóicaseopaleozóicas, que constituem corpos de dimensões alongadas, tendo como encaixantes litotipos de diversas unidades (Jardim de Sá, 1994).

A Bacia Potiguar é a mais oriental das bacias da margem equatorial do Brasil, estando geneticamente relacionada a uma série de bacias neocomianas intracontinentais que compõem 0 Sistema de Rifteamento do Nordeste Brasileiro (Matos, 1987). Sua formação está ligada a dois estágios evolutivos: a fase rifte, iniciada no Eocretáceo, se caracteriza por subsidência tectônica e promoveu a formação de grábens assimétricos e altos internos, 


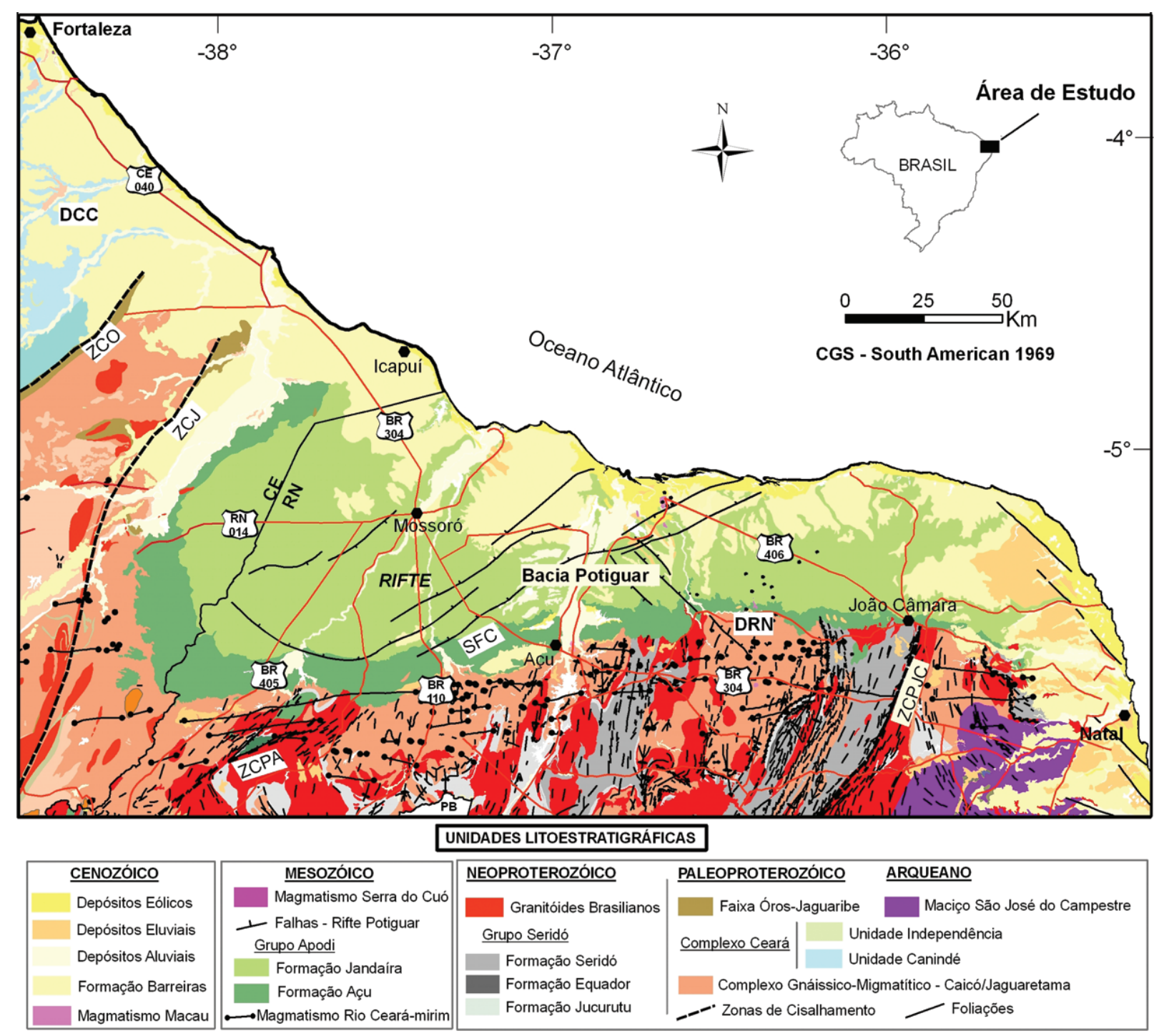

Figura 1 - Mapa Geológico da porção emersa da Bacia Potiguar (modificado de CPRM, 2003 e Angelim, 2006). Domínios Crustais: DCC - Ceará Central; e DRN Rio Grande do Norte. Zonas de Cisalhamento: ZCO - Orós; ZCJ - Jaguaribe; ZCPA - Portalegre; ZCPJC - Picuí-João Câmara; e SFC - Sistema de Falhas Carnaubais.

que correspondem a cristas alongadas do embasamento que separam os principais grábens; e a fase pós-rifte, que compreende uma ampla subsidência térmica, onde se depositaram sequências transicionais e flúvio-marinhas, além de eventos ígneos importantes. As sequências tectono-sedimentares da Bacia Potiguar estão subdivididas em três grupos (Araripe \& Feijó, 1994): Areia Branca, Apodi e Agulha, com sedimentação ocorrida durante 0 Neocomiano até 0 recente.

0 Grupo Areia Branca é constituído por rochas sedimentares clásticas, constituídas por depósitos de origem fluvial, lacustres e deltáicos. 0 Grupo Apodi (Fig. 1) é constituído pelas formações, da base para o topo: a) Formação Açu, identifi- cada pela presença de pacotes de arenito com intercalações de folhelho e argilito; b) Ponta do Mel, composta por calcarenitos e calcilutitos; c) Quebradas, composta por arenitos, folhelhos e siltitos; e d) Jandaíra, que corresponde à única seção carbonática de alta energia sobreposta a Formação Açu (Sampaio \& Schaller, 1968). É composta por calcarenitos bioclásticos com foraminíferos bentônicos e algas verdes em sua porção proximal e mudstones e wackstones na porção distal (Araripe \& Feijó, 1994). Segundo Tibana \& Terra (1981) e Pessoa Neto et al. (2007), os sistemas deposicionais foram planícies de maré, lagunas rasas, plataforma rasa e mar aberto. Na porção submersa da Bacia Potiguar, ocorre o Grupo Agulha, de idade campaniana 
à terciária, composta por uma sequência progradacional de rochas siliciclásticas, carbonatos, folhelhos e turbiditos. Os grupos Apodi e Agulha são parcialmente recobertos pela Formação Barreiras, que é composta por conglomerados e arenitos, que representam depósitos de sistemas fluviais e costeiros.

Segundo Oliveira (1998), a Bacia Potiguar, no seu desenvolvimento, evidencia três atividades ígneas. 0 Enxame de Diques Rio Ceará-Mirim (150 a $120 \mathrm{Ma}$ ) está inserido dinamicamente no contexto que precedeu a abertura do Atlântico Oriental. Os diques se distribuem em faixa alongada E-W/NE-SW por mais de $800 \mathrm{~km}$ (Fig. 1). Concomitante à deposição da Formação Jandaíra, durante o Campaniano/Santoniano, instalou-se um pulso ígneo de afinidade alcalina, denominado de Magmatismo Serra do Cuó, que "cozinhou" e soergueu os arenitos da Formação Açu. Por fim, o Magmatismo Macau desenvolveu-se entre 45 e 25 Ma. Ocorre sob forma de plugs, diques, derrames e soleiras. Configura uma faixa com largura em torno de $60 \mathrm{~km}$ e direção N-S, sugerindo um campo de stress extensional E-W durante sua intrusão.

\section{MAGNETOMETRIA}

0 conjunto de dados aeromagnéticos, utilizado neste trabalho, foi cedido pela Agência Nacional do Petróleo, Gás Natural e Biocombustíveis (ANP), na forma de arquivos digitais. Tais dados foram levantados no âmbito do Projeto Bacia Potiguar pela Petrobras, entre dezembro de 1986 e fevereiro de 1987. Foi voado um total de $26.537 \mathrm{~km}$ de linhas geofísicas, com intervalo de amostragem de $100 \mathrm{~m}$ e com uma altitude média em relação ao terreno de $500 \mathrm{~m}$. As linhas de voo têm direção N20 ${ }^{\circ} \mathrm{W}$ e estão espaçadas de 2 km e $4 \mathrm{~km}$. Já as linhas de controle de qualidade do levantamento foram voadas na direção $\mathrm{N} 70^{\circ} \mathrm{E}$ e possuem um espaçamento de 5 e $10 \mathrm{~km}$ (Fig. 2).

0 processamento dos dados magnéticos consistiu em uma análise da qualidade e consistência dos registros do campo geomagnético, sendo excluídas as linhas de controle do levantamento, além de dados espúrios detectados nas linhas de voo. 0 mapa do campo magnético anômalo, ou seja, após a retirada da componente principal do campo geomagnético (International Geomagnetic Reference Field - IGRF), foi gerado através de uma malha regular de $500 \mathrm{~m}$, usando o método de interpolação kriging. Após esse procedimento, foram aplicadas diversas técnicas de filtragem, com intuito de aumentar a relação sinal/ruído e realçar características específicas das fontes magnéticas, entre elas os filtros cosseno direcional, redução ao polo e sinal analítico 3-D.

0 filtro cosseno direcional é utilizado quando surge nos dados interpolados um ruído direcional devido à alta concentração de informaç̧̃̃es ao longo das linhas de voo do aerolevantamento, interferindo na resposta magnética das fontes (Cordell et al., 1992). Usou-se a seguinte fórmula no cálculo do filtro cosseno direcional:

$$
L(E, N)=|\cos a(\alpha-\theta+\pi / 2)|,
$$

onde " $L$ " é 0 valor do filtro, dado em coordenadas geográficas, " $\alpha$ " é 0 grau de suavização, $a$ é a direção da feição e $\theta$ é a direção do filtro.

A redução ao polo magnético consiste em fazer com que a anomalia magnética de uma fonte geológica local seja independente da direção da indução do campo geomagnético (Telford et al., 1998). Para a aplicação desse filtro, é necessário conhecer a inclinação e declinação do campo geomagnético da região na época do levantamento, cujos valores, para o Projeto Bacia Poti-

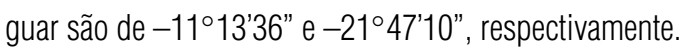

0 sinal analítico tridimensional corresponde a uma gama de métodos automáticos que são baseados no uso dos gradientes vertical e horizontais das anomalias (Nabighian, 1984; Roest et al., 1992). Tem como característica amplificar os curtos e atenuar os longos comprimentos de onda do sinal geofísico nas três direções ortogonais, realçando as bordas e os contatos de feições geológicas e falhas.

A amplitude do sinal analítico é expressa por um vetor de adição das derivadas de segunda ordem das componentes reais nas direções $x$ e $y$ e na componente imaginária na direção $z$, que realiza um processo de varredura para localizar contatos magnéticos e suas profundidades,

$$
|A|=\sqrt{\frac{\partial^{2} T}{\partial x^{2}}+\frac{\partial^{2} T}{\partial y^{2}}+\frac{\partial^{2} T}{\partial z^{2}}},
$$

onde $A$ é a amplitude do sinal analítico, $T$ o campo geomagnético, e $\partial x, \partial y$ e $\partial z$ são as derivadas parciais de segunda ordem nas direções ortogonais $x, y$ e $z$, respectivamente (Reynolds, 1997).

A fase do sinal analítico é definida pelo ângulo formado entre os vetores imaginários da segunda derivada em $z$ e os vetores reais das segundas derivadas em $x$ e $y$. Essa expressão permite estimar o mergulho e 0 contraste de susceptibilidade magnética das fontes causadoras de anomalias. A fase do sinal analítico é dada por

$$
F=\frac{\frac{\partial^{2} T}{\partial z^{2}}}{\sqrt{\frac{\partial^{2} T}{\partial x^{2}}+\frac{\partial^{2} T}{\partial y^{2}}}}
$$




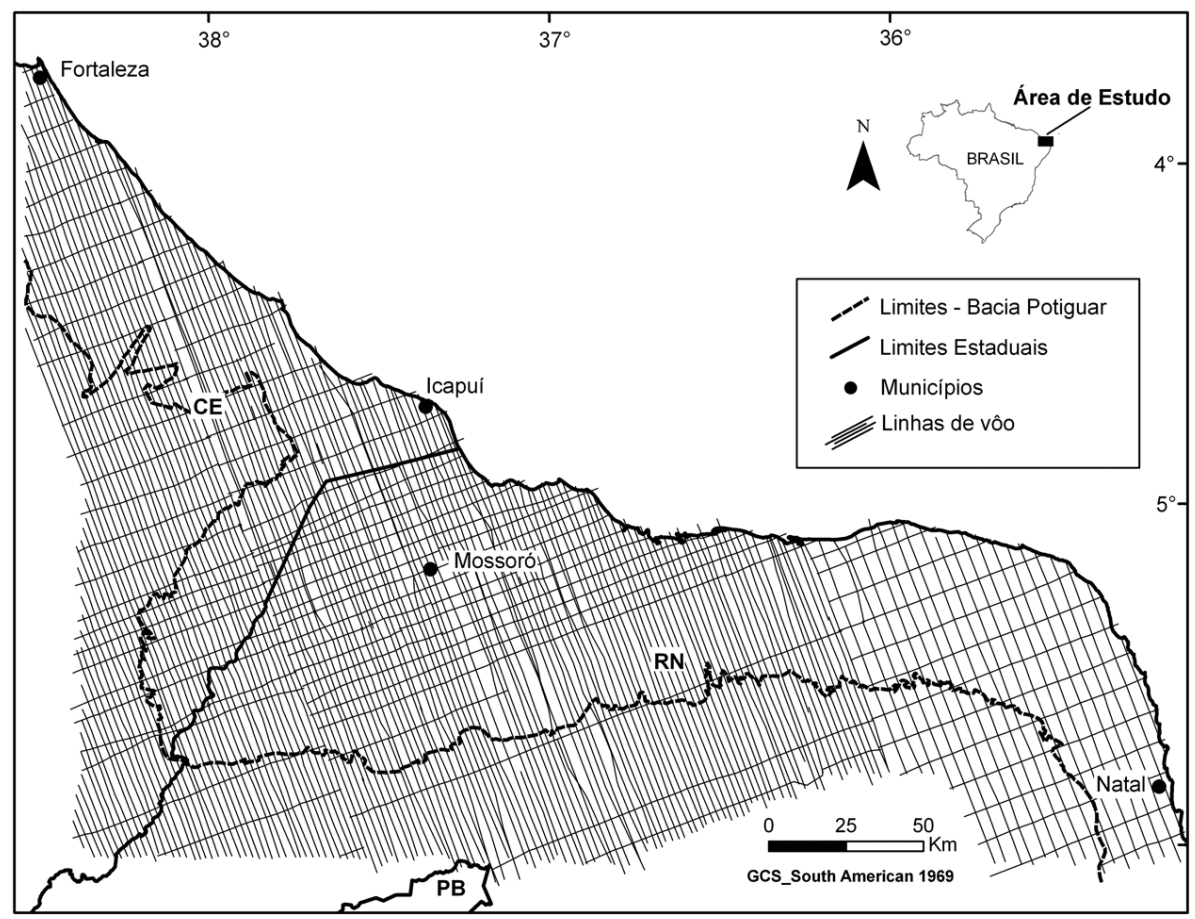

Figura 2 - Mapa das linhas de voo do levantamento aerogeofísico do Projeto Bacia Potiguar. As linhas de voo têm direção $\mathrm{N} 20^{\circ} \mathrm{W}$ e as linhas de controle do levantamento possuem direção $\mathrm{N} 70^{\circ} \mathrm{E}$.

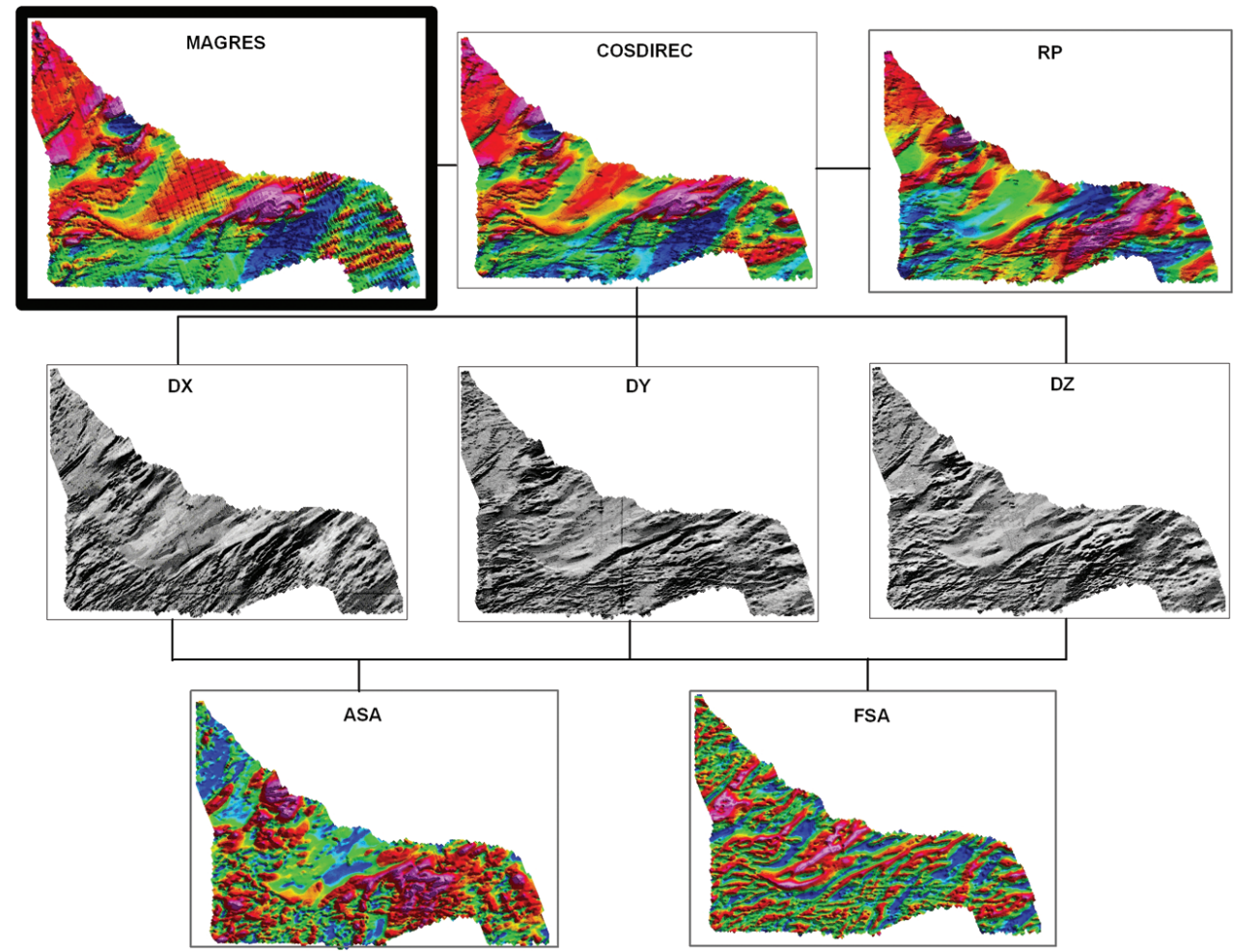

Figura 3 - Etapas de processamento dos dados aeromagnéticos do Projeto Bacia Potiguar. MAGRES - Campo magnético anômalo residual; COSDIREC - Campo magnético anômalo residual, após aplicação do filtro cosseno direcional; RP - Campo magnético reduzido ao polo; DX - Derivada horizontal em X; DY - Derivada horizontal em Y; DZ - Derivada vertical; ASA - Amplitude do sinal analítico; FSA - Fase do sinal analítico. 
A Figura 3 mostra as etapas do processamento dos dados magnéticos para a área da Bacia Potiguar emersa.

\section{Assinatura magnética da Bacia Potiguar}

A assinatura magnética do arcabouço estrutural da Bacia Potiguar mostra uma configuração complexa com extensos alinhamentos principais de direção NE-SW e subordinados na direção E-W (Fig. 4). Anomalias com valores negativos e de maior comprimento de onda (>50 km) ocorrem associadas às feições estruturais de caráter mais profundo, como por exemplo, 0 gráben principal da bacia, situado na parte centro-norte da área. Os mapas de anomalias reduzidas ao polo (Fig. 4a) e amplitude do sinal analítico 3-D foram utilizados para a determinação de domínios magnéticos (Fig. 4c). Enquanto que os lineamentos magnéticos foram traçados com base nos mapas de amplitude e fase do sinal analítico (Fig. 4b). Os principais domínios magnéticos são descritos a seguir:

0 Domínio Magnético Óros (DM0) localiza-se na porção NW da área, apresentando um relevo magnético com amplitudes elevadas (200 nT) (Fig. 4a). Anomalias positivas de forma alongada ocorrem segundo a direção NE-SW, estando associadas aos prolongamentos das ZCO e ZCJ (Anomalias "B" na Fig. 4a). No extremo NW da área, notam-se fortes picos magnéticos de grande amplitude (200 nT) (Anomalia "A" na Fig. 4a), que estão relacionados a rochas magmáticas peralcalinas da Unidade Canindé (Fig. 1). Mais a sudeste, destaca-se um forte gradiente magnético de $4500 \mathrm{nT} / \mathrm{km}$ (Fig. 4a) de forma elipsoidal, com eixo principal ENE-WSW e uma área superficial em torno de $500 \mathrm{~km}^{2}$ (Anomalia "C" na Fig. 4a). Essa feição, também ocorre no mapa de anomalias gravimétricas residuais, 0 que denota 0 caráter local mais máfico e denso de uma unidade geológica não aflorante, recoberta por rochas sedimentares e sedimentos costeiros recentes.

0 Domínio Magnético Jaguaribe (DMJ) apresenta anomalias positivas e negativas de curto comprimento de onda e formas assimétricas, orientadas segundo a direção NE-SW, mais a norte, e inflexões de E-W para NW-SE, a sudeste do Rifte Potiguar (Anomalia "F" na Fig. 4a). Esse domínio está inserido na borda oeste da Bacia Potiguar, conhecida como Plataforma de Aracati e onde afloram, principalmente, as rochas calcárias e arenitos das formações Jandaíra e Açu, respectivamente.

0 Domínio Magnético Rifte Potiguar (DMRP) compreende toda porção rifte da bacia. Possui relevo magnético bem suave, com um padrão de anomalias de médio a longo comprimento de onda, de direção preferencial NE-SW e leves descontinuidades que são associadas a lineamentos de direção NW-SE. Na parte mais central, os principais grábens do Rifte Potiguar destacamse por apresentar anomalias negativas de comprimento de onda de médio a longo, orientadas segundo direções NE-SW e E-W (Anomalias "D" na Fig. 4a), associadas aos espessos pacotes sedimentares no interior da bacia (depocentros). Merecem destaque, ainda, expressivos picos magnéticos de grande amplitude (Anomalias "E" na Fig. 4a), bem evidenciados no mapa do sinal analítico 3-D (2000 nT/km). Esses máximos correspondem a altos internos no arcabouço da bacia e/ou corpos basálticos não aflorantes, provavelmente relacionados ao Vulcanismo Macau, na porção mais próxima à margem continental.

Esse domínio é limitado por duas longas faixas anômalas positivas, que compreendem as ombreiras do semi-gráben principal, tendo direções $\mathrm{N} 45^{\circ} \mathrm{E}$ (a oeste) e $\mathrm{N} 60^{\circ} \mathrm{E}$ (a leste). Essa última orientação corresponde à continuidade da Zona de CisaIhamento Portalegre, que foi reativada durante a abertura do rifte no Cretáceo Inferior, proporcionando a formação do Sistema de Falhas Carnaubais (SFC na Fig. 1).

0 Domínio Magnético Carnaubais (DMC) é marcado por um relevo magnético bastante acidentado, inserido numa zona de inflexão dos lineamentos magnéticos de $\mathrm{E}-\mathrm{W}$, nas porções sul e sudeste, para NE-SW, mais para norte (Fig. 4). 0 embasamento paleoproterozóico do Complexo Gnaíssico-Migmatíitico, as sequências supracrustais das faixas Jaguaribe e Seridó, bem como intrusões graníticas compõem a geologia de superfície deste domínio. Na região norte desse domínio, uma zona anomalamente negativa bastante expressiva de direção principal NESW, ocorre paralela ao limite leste do Rifte Potiguar (SFC) e atinge valores de até -200 nT. Análises estruturais em diversos afloramentos na parte central da BP, realizadas por Moura (2004), mostram um padrão estrutural orientado segundo a direção NW-SE. Esta estruturação local destoa do padrão anômalo observado nos mapas magnéticos, marcado por anomalias dispostas na direção NE-SW. Tal fato pode ser atribuído ao caráter bastante raso dessas estruturas, tendo pouca influência nos mapas magnéticos regionais.

0 Domínio Magnético Seridó (DMS) Iocaliza-se a oeste do DMC (Fig. 4C), onde destaca-se um forte dipolo magnético assimétrico, com amplitudes de até $265 \mathrm{nT}$ e um trend principal NE-SW (Fig. 4b). Na parte sul, destacam-se anomalias positivas de curto comprimento de onda alongadas na direção EW, associadas ao intenso vulcanismo (Magmatismo Rio CearáMirim), ocorrido durante a abertura do Oceano Atlântico, no Cretáceo Inferior. É notório, nos mapas magnéticos (Figs. 4a e 4b), que essas anomalias se distribuem ao longo de toda porção sul da Bacia Potiguar, revelando a forte atividade vulcânica desse 

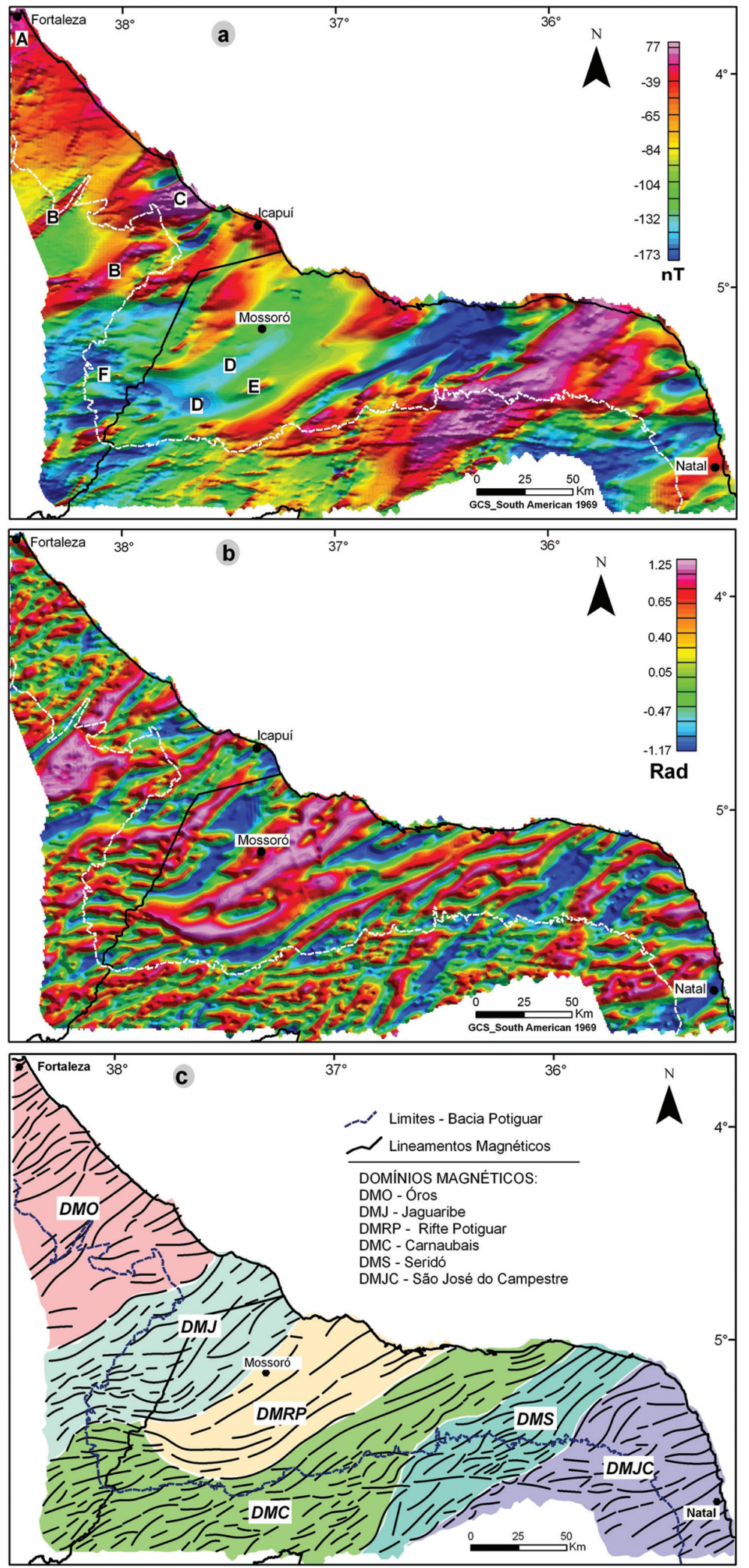

Figura 4 - Mapa de anomalias magnéticas reduzidas ao polo (a), as anomalias magnéticas de A até $F$ encontram-se descritas no texto, mapa da fase do sinal analítico 3-D (b) e mapa magnético interpretado (c). 
evento. Afloram ainda, na região desse domínio, rochas do Complexo Gnáissico-Migmatíitico e da sequência supracrustal Seridó, granitos cálcio-alcalinos e as rochas sedimentares da bacia, mais a norte (Fig. 1).

0 Domínio Magnético São José do Campestre (DMJC) é representado por anomalias magnéticas essencialmente negativas de amplitudes médias a altas (-50 a -200 nT) e com direção preferencial para NE-SW e E-W (Fig. 4a). Esse domínio recobre as porções aflorantes da Faixa Seridó e do Complexo GnáissicoMigmatítico, sendo o limite oeste deste domínio aparentemente marcado pela ZCPJC, associada a um forte lineamento magnético positivo de direção N-S. Os trends principais dos lineamentos magnéticos possuem direção NE-SW e E-W, mais a sul. A porção centro-norte desse domínio apresenta intensa atividade sísmica (Nogueira, 2008), estando associada a uma região anômala de direção NE-SW, no extremo NE da área de estudo.

\section{GRAVIMETRIA}

Os dados gravimétricos terrestres utilizados nesta pesquisa provêm de vários levantamentos independentes realizados por diversas universidades (UFC, UFRN, USP), instituiçõ̃es de pesquisa e órgãos governamentais (Petrobras, CPRM, IBGE, ON). Na parte submersa da bacia, os dados gravimétricos são oriundos do banco de dados geofísicos GEODAS (Geophysical Data System - NOAA), bem como do Projeto EQUANT I (Petrobras/Oregon State University - OSU). A Figura 5 apresenta a distribuição das estações de medidas na área pesquisada.

As correções da atração luni-solar, latitude, elevação e Bouguer foram previamente efetuadas no conjunto de dados gravimétricos terrestres. Nas medidas realizadas no mar foram feitas adicionalmente a correção de Eötvös e a correção Bouguer.

0 mapa de anomalias Bouguer (Fig. 5) foi confeccionado através da interpolação dos dados gravimétricos em uma maIha regular de 1,0 km, utilizando o método kriging. As anomalias Bouguer apresentam um expressivo gradiente gravimétrico da ordem de 1,2 mGal $/ \mathrm{km}$, cujos valores variam de $-15 \mathrm{mGal}$, no interior do continente, a $160 \mathrm{mGal}$, nas regiões oceânicas mais profundas, aumentando de sudoeste para nordeste. 0 forte conteúdo de longo comprimento de onda do campo gravimétrico na porção setentrional da margem continental do Nordeste do Brasil é ocasionado pelo afinamento crustal em direção a crosta oceânica em uma típica região de margem continental passiva (de Castro et al., 2007).

As componentes regional e residual do campo gravimétrico foram separadas através de um filtro de separação regional- residual, que baseia-se na distribuição gaussiana das fontes gravimétricas em função de suas profundidades. Este filtro consiste de um operador matemático que atua como passa-baixa ou passaalta das frequências do sinal escolhido no domínio do número de ondas. 0 espectro de potência do sinal gravimétrico foi gerado afim de que se pudessem obter melhores resultados no que diz respeito à separação espectral das fontes rasas e profundas, causativas das anomalias gravimétricas. 0 trend gravimétrico regional da área pesquisada pôde ser individualizado satisfatoriamente (Fig. 6a), realçando a resposta gravimétrica das heterogeneidades crustais mais rasas, expressas no mapa de anomalias residuais (Fig. 6b).

0 mapa de anomalias gravimétricas regionais é caracterizado por anomalias gravimétricas bastante suaves de longo comprimento de onda, associadas a um gradiente gravimétrico positivo de caráter regional (-50 a $150 \mathrm{mGal})$, com sentido de SW para NE (Fig. 6a). Esse aumento contínuo do campo gravimétrico está associado ao afinamento crustal típico de margens continentais passivas como a do nordeste brasileiro (de Castro et al., 1998). Nas partes central e oeste da porção emersa da Bacia Potiguar, destaca-se uma anomalia positiva de longo comprimento de onda, que certamente reflete uma subida suave do manto em uma região de rifte abortado. Uma anomalia negativa $(-5 \mathrm{mGal})$, com longo a médio comprimento de onda (>50 km) e eixo principal WNW-ESSE, surge a NW da cidade de Mossoró (RN) (Fig. 6a), sugerindo a presença de um déficit de massa profundo na NW do Rifte Potiguar. Os trends gravimétricos regionais indicam uma compartimentação crustal na direção NE-SW, com inflexões para NW-SE no limite oeste do rifte. A presença de lineamentos gravimétricos coincidentes com a borda falhada do semi-gráben da bacia sugere que o mesmo seria fruto da reativação de uma zona de fraqueza crustal pretérita bastante profunda e de idade neoproterozóica, relacionada à prolongação da Zona de Cisalhamento Portalegre (ZCPA na Fig. 1).

0 mapa de anomalias gravimétricas residuais (Fig. 6b) foi usado na interpretação da assinatura gravimétrica do arcabouço estrutural da BP. Seis domínios gravimétricos podem ser individualizados com base em suas respostas gravimétricas (Fig. 6c), como descritos abaixo:

No Domínio Gravimétrico Óros (DGO), a região N-NW, é dominada por anomalias de médio comprimento de onda, com vaIores baixos a intermediários, variando entre -6 a 2 mGal. Nessa área, afloram sedimentos e rochas da Formação Barreiras, que estão sobrepostas aos litotipos do Complexo Ceará, onde expressões magmáticas locais estão associadas a anomalias de maior amplitude, de até 4 mGal. A porção sul desse domínio cor- 


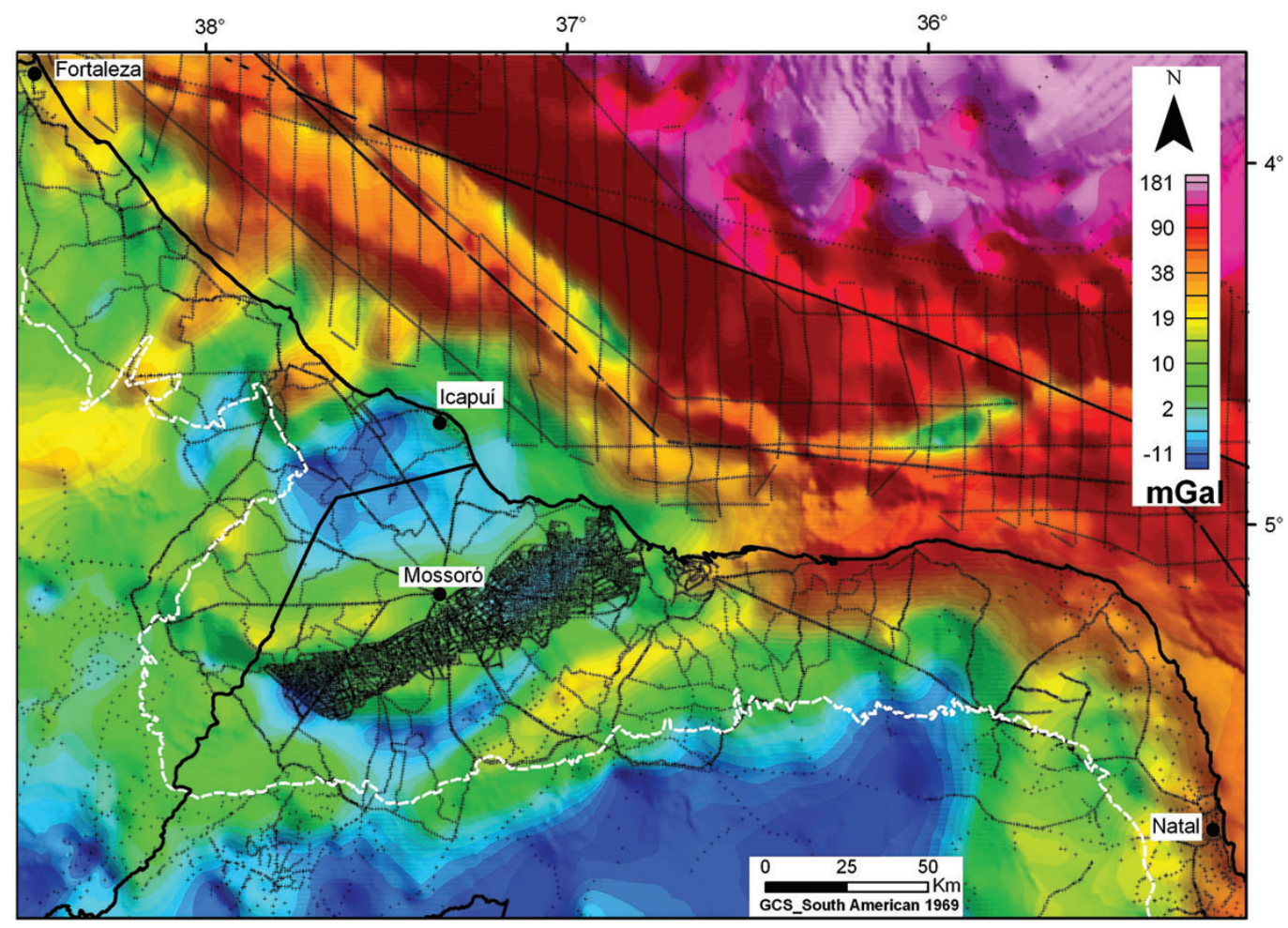

Figura 5 - Mapa de anomalias Bouguer com a localização das estações gravimétricas do arcabouço estrutural das porções emersa e submersa (Projeto EQUANT I) da Bacia Potiguar.

responde a uma extensa faixa anômala, com altos valores de gravidade (10 a $15 \mathrm{mGal}$ ), disposta de forma alongada, na direção $40^{\circ} \mathrm{Az}$, com curto comprimento de onda do sinal geofísico (Fig. 6b). Está diretamente associado à sequência de rochas supracrustais paleoproterozóicas da Faixa Orós, cujo limite leste é marcado pela Zona de Cisalhamento Óros (ZCO na Fig. 1). Este domínio gravimétrico aparentemente marca a região limítrofe entre dois blocos crustais, os domínios Ceará Central (DCC) e Rio Grande do Norte (DRN).

0 Domínio Gravimétrico Jaguaribe (DGJ) apresenta relevo gravimétrico bastante acidentado com anomalias de grandes amplitudes (-10 a $15 \mathrm{mGal}$ ), com destaque para um expressivo máximo gravimétrico (15 mGal) no extremo norte desse domínio (Figs. 6b e 6c). Anomalias magnéticas de grande amplitude ocorrem na região, ocupando uma distribuição espacial bastante semelhante (Fig. 4). A geologia local de superfície diz respeito a rochas supracrustais da Faixa Jaguaribe, mais a sul, que estão recobertas pelas rochas sedimentares da Formação Barreiras e sedimentos recentes, na região anômala.

0 Domínio Gravimétrico Rifte Potiguar (DGRP) é representado por uma assinatura gravimétrica bastante acentuada, com anomalias negativas e positivas, variando de -10 a $10 \mathrm{mGal}$ e com direção principal para NE-SW. Esse domínio é limitado por expressivos lineamentos gravimétricos positivos, variando entre 5 e $10 \mathrm{mGal}$, a oeste e 8 a $15 \mathrm{mGal}$ a leste, respectivamente (Fig. 6b). Este último marca a borda falhada do rifte, controlada pelo Sistema de Falhas Carnaubais (SFC na Fig. 1). Na parte interna, ocorrem anomalias negativas de direção NE-SW e E-W que representam os principais depocentros do semi-gráben principal da Bacia Potiguar. 0 DGRP é, ainda, realçado por picos gravimétricos positivos de grande amplitude (10 mGal), que estão relacionados a altos estruturais recobertos pelo pacote sedimentar da bacia. Por fim, lineamentos gravimétricos de direção NWSE estão associados ao Sistema de Falhas Poço Verde-Caraúbas, obtidos a partir de imagens SRTM (Santos et al., 2009). Hackspacher et al. (1985) interpretam essas estruturas de direção NW-SE como produto de reativações pós-campanianas. Matos (1992), por sua vez, define estas estruturas como sendo falhas de transferência durante a fase rifte inicial.

0 Domínio Gravimétrico Carnaubais (DGC) diz respeito a um marcante lineamento gravimétrico de forma alongada na direção $60^{\circ} \mathrm{Az}$, com valores máximos de $15 \mathrm{mGal}$, que está associado 

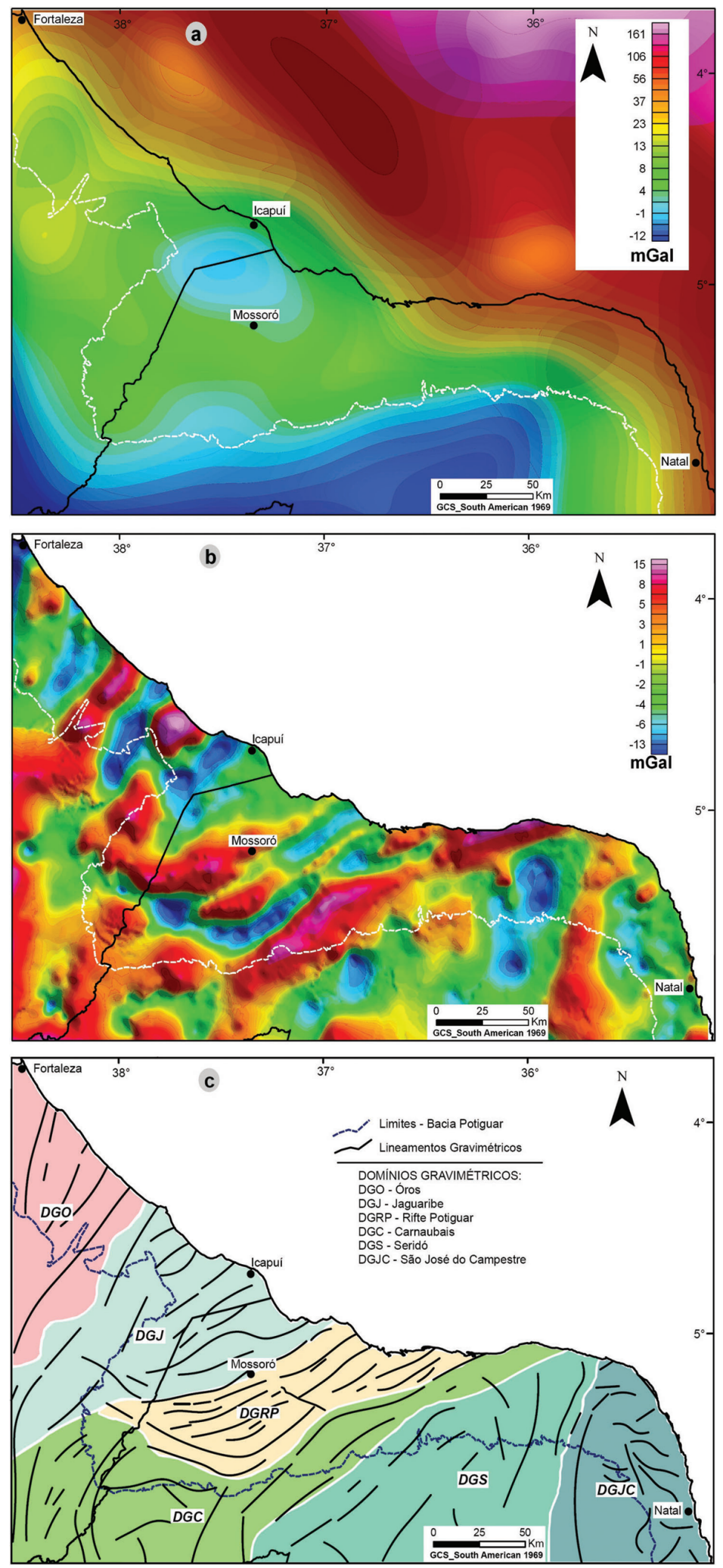

Figura 6 - Mapa de anomalias gravimétricas regionais (a), mapa de anomalias gravimétricas residuais (b) e domínios gravimétricos do arcabouço estrutural da Bacia Potiguar (c). 
à ZCPA, no limite sul da bacia, e 0 seu prolongamento para NE ao longo do SFC (Fig. 6b). Mais a sul, anomalias negativas de longo comprimento de onda (30 km) estão relacionadas ao Complexo Gnáissico-Migmatítico e corpos intrusivos de suítes alcalinas (Fig. 1).

0 Domínio Gravimétrico Seridó (DGS) está associado aos litotipos da sequência supracrustal da Faixa Seridó, suítes granitóides e rochas do Complexo Gnáissico-Migmatítico localizados na região sul e sudeste da área. É marcado por anomalias gravimétricas negativas nas direções N-S, NE-SW e NW-SE. Seu contato leste encontra-se bem definido por um alinhamento gravimétrico positivo de direção N-S, um limite crustal secundário marcado pela Zona de Cisalhamento Picuí-João Câmara (ZCPJC na Fig. 1). Na porção norte, afloram rochas sedimentares do Grupo Apodi e sedimentos recentes do Cenozóico. Esse domínio apresenta anomalias suaves e de longo comprimento de onda (>60 km), decorrentes da baixa cobertura e da má distribuição das estações gravimétricas na região (Fig. 5).

0 Domínio Gravimétrico São José do Campestre (DGJC) representa uma expressiva faixa de anomalias positivas de direção $\mathrm{N}-\mathrm{S}$, com valores em torno de $8 \mathrm{mGal}$ (Fig. 6b). Marca o contato entre dois tipos litológicos distintos, a sequência de rochas supracrustais da Faixa Seridó e os litotipos de alto grau metamórfico do Complexo Gnáissico-Migmatíitico, estruturalmente limitados pela ZCPJC. Os trends principais dos lineamentos gravimétricos coincidem de sobremaneira com as estruturas da região, que possuem direção N-S e NW-SE mais a sul, sofrendo leve inflexão para E-W, adentrando nas rochas sedimentares do Grupo Apodi. A porção ao norte da ZCPJC apresenta intensa atividade sísmica (Nogueira, 2008), o que denota sua movimentação atual, afetando as rochas do embasamento cristalino e sedimentares cretáceas da Bacia Potiguar.

\section{INTEGRAÇÃO DE DADOS GEOFÍSICOS E GEOLÓGICOS}

Os mapas da Figura 7 apresentam a integração das assinaturas magnéticas e gravimétricas com dados geológicos de superfície, além dos principais alinhamentos estruturais. Observa-se uma notável coincidência entre os lineamantos geofísicos e os principais trends estruturais, bem como as extensas zonas de cisaIhamento brasilianas e seus prolongamentos no interior da bacia. A transição entre os domínios magnéticos e gravimétricos Orós (DMO e DGO) e Jaguaribe (DMJ e DGJ) (Figs. 4c, 6c e 7c) representam, provavelmente, a região limítrofe entre os dois blocos crustais dos domínios Ceará Central (DCC) e Rio Grande do Norte (DRN) (Fig. 1). Nessa porção, destacam-se dois for- tes alinhamentos magnético positivo e gravimétrico negativo de direção $30^{\circ} \mathrm{Az}$, associados à Zona de Cisalhamento Jaguaribe (ZCJ na Fig. 7). 0 extremo NE do DCC é marcado por um relevo magnético elevado, com anomalias dispostas na direção NE-SW. Já no DRN, anomalias magnéticas e gravimétricas positivas e negativas possuem grandes semelhanças com as principais estruturas geológicas da região, principalmente, na parte mais a sul onde afloram as rochas do embasamento pré-cambriano (Figs. 1e 7).

Ao longo de toda borda leste do gráben principal da Bacia Potiguar, vários afloramentos atestam para um padrão estrutural bastante complexo e variado, com medidas de falhamentos de direção NE-SW, E-W e NW-SE, sendo a maioria, falhas normais com componentes dextrais (Almeida, 2003; Aquino, 2006). Todas essas feições pontuais estão associadas ao extenso lineamento magnético e gravimétrico positivo de direção principal $\mathrm{N} 60^{\circ} \mathrm{E}$, que representa o Sistema de Falhas Carnaubais, através do prolongamento da ZCPA. A grande quantidade de falhamentos nos pacotes sedimentares do Grupo Apodi é a evidência principal de reativações das zonas de cisalhamentos brasilianas, ocorridas desde 0 fim do Mesozóico até o recente. E são essas regiões, as de maior interesse na prospecção de petróleo e gás na Bacia Potiguar, visto que tais estruturas servem como armadilhas geológicas para o seu armazenamento.

Os mapas geofísicos evidenciam muito bem os limites estruturais entre 0 gráben principal da bacia e 0 seu embasamento cristalino por anomalias positivas alongadas na direção NE-SW (Fig. 7). A porção central do gráben é marcada por anomalias negativas de médio comprimento de onda, onde os máximos negativos correspondem aos depocentros principais da bacia, e ainda, é realçada por picos positivos de grande amplitude que indicam, possivelmente, altos estruturais e, localmente, intrusões básicas e corpos basálticos não aflorantes (Milani \& Latgé, 1987; de Castro et al., 1998).

0 enxame de diques básicos do Vulcanismo Rio Ceará-Mirim está representado nos mapas magnéticos por anomalias de curto comprimento de onda e forma alongada na direção E-W. Este padrão anômalo (Fig. 4) ocorre paralelo ao limite sul da bacia, se sobrepondo as anomalias de maior comprimento de onda, cujas fontes magnéticas são mais profundas. 0 Magmatismo Macau está associado a anomalias positivas de grande amplitude nos mapas magnéticos e gravimétricos (Fig. 7), distribuídas de formas alongadas e arredondadas na porção centro-oeste da área e, possivelmente, na parte rifte da bacia.

Nos domínios gravimétricos Jaguaribe (DGJ) e Rifte Potiguar (DGRP), as anomalias gravimétricas apresentam uma distribuição 

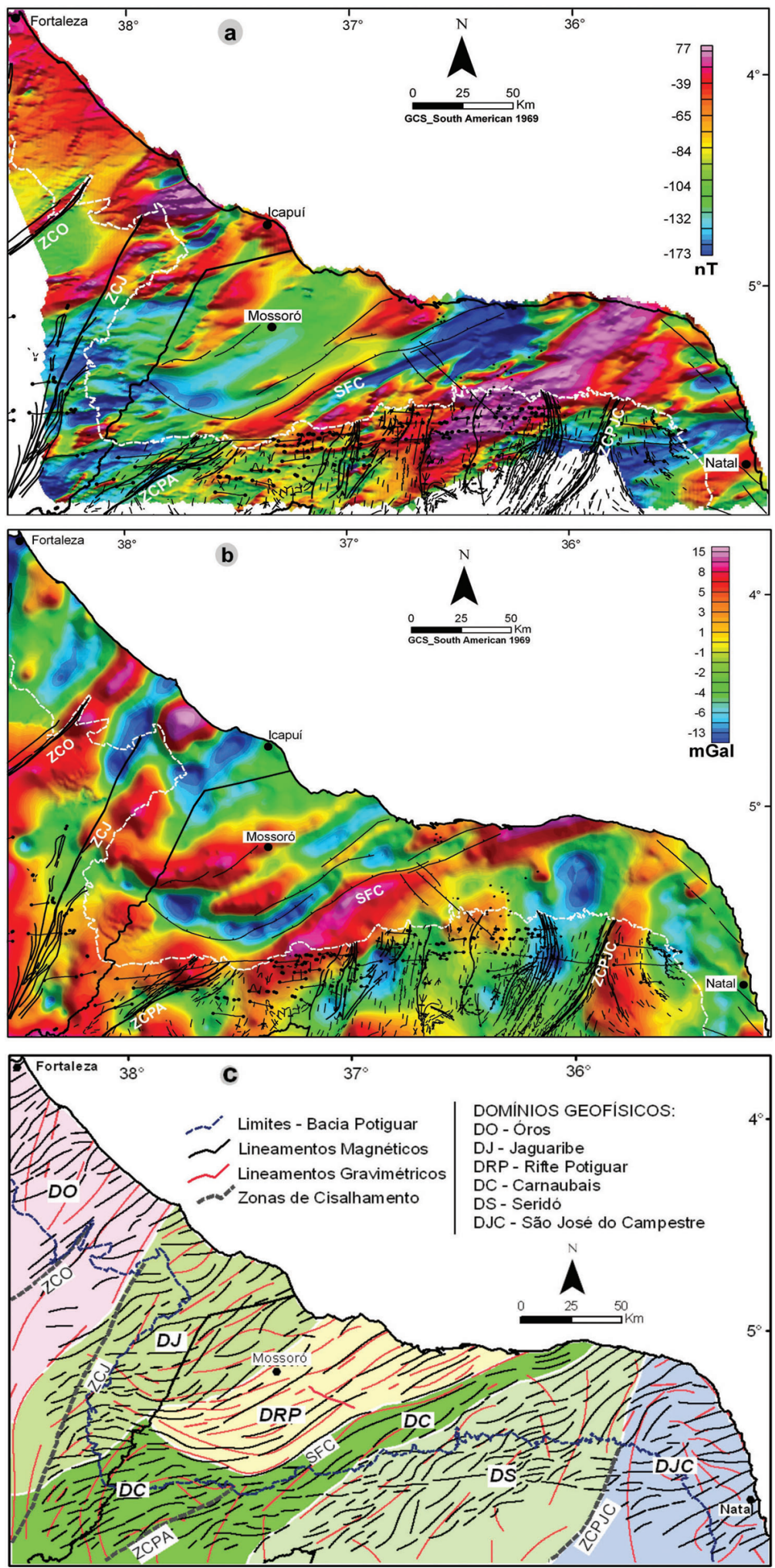

Figura 7 - Integração do mapa de anomalias magnéticas reduzidas ao polo (a), mapa de anomalias gravimétricas residuais (b) e mapa de domínios geofísicos (c) com os principais alinhamentos estruturais e zonas de cisalhamento (ZCO - Orós; ZCJ - Jaguaribe; ZCPA - Portalegre; ZCPJC - Picuí-João Câmara). SFC - Sistema de Falhas Carnaubais. 
dos lineamentos geofísicos em forma de leque (Fig. 7), sendo seus limites laterais representados pelas zonas de cisalhamento Jaguaribe, a oeste, e Portalegre e sua continuação ao longo do Sistema de Falhas Carnaubais, a leste. Nessa região, ocorreu a instalação do Rifte Potiguar. Por sua vez, o limite sul do rifte é marcado pela inflexão de anomalias magnéticas e gravimétricas na direção NW-SE. Tais trends geofísicos sugerem o controle estrutural de feições pretéritas do embasamento na geração de falhas de transferência NW-SE, quando se deu a formação do rifte, no Cretáceo Inferior.

\section{CONCLUSÕES}

A interpretação qualitativa dos mapas de anomalias magnéticas reduzidas ao polo, amplitude e fase do sinal analítico 3-D e anomalias gravimétricas residuais mostram uma complexa estruturação regional de direção NE-SW para toda a porção setentrional da Província Borborema, que condicionou a implantação do Rifte Potiguar.

A fase do sinal analítico revela o predomínio da direção NESW na trama estrutural do embasamento com inflexões sigmoidais E-W e NW-SE, se estendendo pelo interior da bacia.

As anomalias gravimétricas Bouguer e regionais são dominadas por um marcante gradiente gravimétrico do continente para 0 oceano, no sentido SW para NE, seguindo grosseiramente a linha de costa da região, revelando o típico afinamento crustal da margem passiva continental do nordeste brasileiro.

A arquitetura interna do rifte é facilmente delineada no mapa gravimétrico residual, com mínimos coincidindo com os depocentros da bacia e máximos com os altos estruturais ou rochas intrusivas não aflorantes.

Expressivos lineamentos magnéticos e gravimétricos correspondem às megazonas de cisalhamento brasilianas. Os proIongamentos dos trends geofísicos nas porções rifte e pós-rifte da Bacia Potiguar corroboram a assertiva de que estas feições sofreram importantes reativações durante o Cretáceo Inferior, na forma de falhas normais de direção NE-SW e de transferência ou acomodação, com direção preferencial para NW-SE.

Os espessos pacotes sedimentares do gráben principal da Bacia Potiguar estão caracterizados por anomalias magnéticas e gravimétricas negativas de curto comprimento de onda, com direções E-W e NE-SW. Os depocentros estão associados a valores mínimos que chegam a atingir $-180 \mathrm{nT}$ e $-10 \mathrm{mGal}$, respectivamente, caracterizados pelo baixo conteúdo magnético e baixa densidade do pacote sedimentar.

\section{AGRADECIMENTOS}

Os autores agradecem à Agência Nacional do Petróleo, Gás Natural e Biocombustíveis (ANP) pela cessão dos dados geofísicos. N.C. Pedrosa Jr. foi bolsista dos programas PIBIC-UFC-CNPq e CAPES no mestrado, D.L. de Castro é bolsista de produtividade do CNPq e J.P.L. de Matos é bolsista de mestrado da CAPES.

\section{REFERÊNCIAS}

ALMEIDA RB. 2003. Tectônica Rúptil na Região entre Açu e Upanema/ RN, Bacia Potiguar. Relatório de Graduação em Geologia, UFRN, Natal, $72 \mathrm{p}$.

ALMEIDA FFM, BRITO NEVES BB \& CARNEIRO CDR. 2000. The origin and evolution of the South American Platform. Earth Science Reviews, 50: 77-111.

ANGELIM LAA. 2006. Geologia e recursos minerais do Estado do Rio Grande do Norte - Escala 1:500.000. CPRM - Serviço Geológico do Brasil, Recife, $119 \mathrm{p}$.

AQUINO MR. 2006. Mapeamento geológico/morfotectônico da região de Carnaubais-Bacia Potiguar. Relatório de Graduação em Geologia, UFRN, Natal, $82 \mathrm{p}$.

ARARIPE PT \& FEIJÓ FJ. 1994. Bacia Potiguar. Bol. Geoc. Petrobras, 8: 127-141.

BOYCE JI \& MORRIS WA. 2002. Basement-controlled faulting of Paleozoic strata in southern Ontario, Canada: new evidence from geophysical lineament mapping. Tectonophysics, 353: 151-171.

CORDELL L, PHILLIPS JD \& GODSON RH. 1992. US Geological Survey Potential-Field geophysical software, Version 2.0. USGS, Open-File Report, 92-18.

CPRM. Serviço Geológico do Brasil. 2003. Mapa Geológico do Estado do Ceará em escala de 1:500.000. Formato digital: shapefile (ESRI).

DANTAS EL, VAN SCHMUS WR, HACKSPACHER PC, FETTER AH, BRITO NEVES BB, CORDANI U, NUTMAN AP \& WILLIAMS IS. 2004. The 3.4-3.5 Ga São José do Campestre massif, NE Brazil: remnants of the oldest crust in South America. Precambrian Research, 130: 113-137.

DE CASTRO DL, MEDEIROS WE, JARDIM DE SÁ EF \& MOREIRA JAM. 1998. Mapa gravimétrico do Nordeste Setentrional do Brasil e margem continental adjacente: interpretação com base na hipótese de isostasia. Rev. Bras. de Geof., 16(2/3): 115-131.

DE CASTRO DL, OLIVEIRA DC \& CASTELO BRANCO RMG. 2007. On the tectonics of the Neocomian Rio do Peixe rift basin, NE Brazil: lessons from gravity, magnetics and radiometric data. J. South American Earth Sciences, 24: 184-202.

FETTER AH, DOS SANTOS TJS, VAN SCHMUS WR, HACKSPACHER PC, BRITO NEVES BB, ARTHAUD M, NOGUEIRA NETO JA \& WERNICK 
E. 2003. Evidence for Neoproterozoic continental arc magmatism in the Santa Quitéria Batholith of Ceará State, NW Borborema Province, NE Brazil: Implications for the assembly of west Gondwana. Gondwana Research, 6(2): 265-273.

HACKSPACHER PC, CORSINO AR, SRIVASTAVA NK \& TIRIBA VF. 1985. A Falha de Afonso Bezerra como evidência de significativo tectonismo frágil NW-SE, na Bacia Potiguar emersa - RN. Boletim do Departamento de Geologia/UFRN, Natal, 10: 33-44.

JARDIM DE SÁ EF. 1994. A evolução proterozóica da Província Borborema. In: Simpósio de Geologia do Nordeste, 11., Natal. Atas... Natal: SBG/Núcleo NE, 291-316.

MATOS RMD. 1987. Expressão sísmica de prováveis falhas de transferência na Bacia Potiguar emersa e Gráben de Jacaúna/CE. In: Seminário de Geofísica, 2., Nova Friburgo. Anais... Nova Friburgo: Petrobras/Depex.

MATOS RMD. 1992. Deep seismic profiling, basin geometry and tectonic evolution of intracontinental rift basins in Brazil. Tese de Doutorado, Cornell Univ., U.S.A., 276 p.

MILANI E \& LATGÉ MA. 1987. Modelagem Gravimétrica da porção terrestre da Bacia Potiguar e suas implicações geotectônicas. Bol. Geoc. Petrobras, RJ, 1(1): 75-85.

MOURA EN. 2004. Mapeamento Estrutural na Região de Felipe Guerra RN, Bacia Potiguar. Relatório de Graduação em Geologia, UFRN, Natal, $100 \mathrm{p}$.

NABIGHIAN M. 1984. Toward a three-dimensional automatic interpretation of potential field data via generalized Hilbert transforms: fundamental relations. Geophysics, 49: 780-786.

NICOLAS A, ACHAUER U \& DAIGNIERES M. 1994. Rift initiation by lithospheric rupture. Earth Planet. Sci. Lett., 123(1-4): 281-298.

NOGUEIRA FCC. 2008. Estruturas Tectônicas Cenozóicas na Porção Leste da Bacia Potiguar - RN. Tese de Doutorado, UFRN, Natal, $156 \mathrm{p}$.
OLIVEIRA DC. 1998. Evolução Magmática da Bacia Potiguar. In: Congresso Brasileiro de Geologia, 40., Belo Horizonte. Anais... Belo Horizonte: SBG, p. 102.

PARENTE CV \& ARTHAUD M. 1995. 0 sistema Orós-Jaguaribe no Ceará, NE do Brasil. Revista Brasileira de Geociências, 25: 21-32.

PESSOA NETO OC, SOARES UM, SILVA JGF, ROESNER EH, FLORENCIO CP \& SOUZA CAV. 2007. Bacia Potiguar. Bol. Geoc. Petrobras, 15(2): 357-369.

REYNOLDS JM. 1997. An introduction to applied and environmental geophysics. John Wiley \& Sons, $796 \mathrm{p}$.

ROEST WR, VERHOEF J \& PILKINGTON M. 1992. Magnetic interpretation using the 3-D analytical signal. Geophysics, 57(1): 116-125.

SAMPAIO AV \& SCHALLER H. 1968. Introdução à Estratigrafia da Bacia Potiguar. Rio de Janeiro. Boletim Técnico da Petrobras, 11(1): 19-44.

SANTOS RD, SOUSA MOL, LIMA ENM \& BEZERRA FHR. 2009. Deformação Pós-Campaniana do Sistema de Falhas Poço Verde-Caraúbas, Bacia Potiguar. In: Simpósio Nacional de Estudos Tectônicos, 12., Ouro Preto. Resumos... Ouro Preto: SBG, Universidade Federal de Ouro Preto. CD-ROM.

SYKES LR. 1978. Intraplate seismicity, reactivation of preexisting zones of weakness, alkaline magmatism and other tectonism post-dating continental fragmentation. Rev. Geophys., 16: 621-688.

TELFORD WM, GELDART LP, SHERIFF RE \& KEYS DA. 1998. Applied Geophysics. (5 ed.), Cambridge University Press, $860 \mathrm{p}$.

TIBANA P \& TERRA GJS. 1981. Seqüências carbonáticas do Cretáceo na Bacia Potiguar. Boletim Técnico da Petrobras, 24(3): 174-183.

VASCONCELOS AM, PRADO FD, CAVALCANTE JC, PAIVA IO, SILVA LC, MARQUES MTG, SOUZA EC, GOMES FEM, FRIZZO SJ, RODRIGUES JC \& DELGADO IM. 1998. Folha Iguatu (Folha SB. 24-Y-B) - Ceará. Escala $1: 250.000$.

\section{NOTAS SOBRE OS AUTORES}

Nilo Costa Pedrosa Júnior é geólogo e concluiu o mestrado em Geologia, na área de Geodinâmica e Recursos Minerais pela UFC em 2010. Geociências, com ênfase em Geofísica Aplicada ao estudo de bacias sedimentares e cartografia geofísica regional. É membro da Sociedade Brasileira de Geofísica.

David Lopes de Castro é geólogo pela UFRN, mestre em Geofísica pela UFPA e concluiu o doutorado em Geofísica na Christian-Albrechts Universität - Kiel (Alemanha) em 1995. É professor adjunto do Departamento de Geologia da Universidade Federal do Rio Grande do Norte. Atua na área de Geociências, com ênfase em Geofísica Aplicada ao estudo de bacias sedimentares, cartografia geofísica regional, hidrogeologia e meio ambiente. É membro da Sociedade Brasileira de Geofísica e da Sociedade Brasileira de Geologia.

João Paulo Lopes de Matos é geólogo e cursa o Programa de Pós-Graduação em Geologia - UFC. Atua na área de Geociências, com ênfase em Geofísica Aplicada ao estudo de bacias sedimentares e cartografia geofísica regional. É membro da Sociedade Brasileira de Geofísica. 